\title{
Stability analysis of rock slope and calculation of rock lateral pressure in foundation pit with structural plane and cave development
}

Jin Xu (D137112492@qq.com)

China University of Mining and Technology, Xu Zhou

Yansen Wang

China University of Mining and Technology, Xu Zhou

\section{Research Article}

Keywords: Karst cave development, rock foundation pit, upper bound analysis, rock lateral pressure

Posted Date: December 9th, 2021

DOI: https://doi.org/10.21203/rs.3.rs-1150045/v1

License: (c) (1) This work is licensed under a Creative Commons Attribution 4.0 International License.

Read Full License 


\title{
Stability analysis of rock slope and calculation of rock lateral
}

\section{pressure in foundation pit with structural plane and cave \\ development}

\begin{abstract}
Jin $\mathrm{Xu}^{1} \quad$ Yansen Wang ${ }^{1}$
(1. State key Laboratory for Geomechanics and Deep Underground Engineering, China University of Mining and Technology, Xu Zhou, 221116, China)

Abstract: In this study, numerical simulations were carried out to analyze the influence of caves in different positions and shapes, in combination with structural planes, on the stability of the slope and the failure characteristics of a rock slope in a deep foundation pit with high inclination structural planes and cave development. The schemes for substituting a single karst cave for karst caves were constructed. Based on the penetration failure characteristics of karst caves between parallel structural planes, methods for calculating the safety factor of the rock foundation pit and the upper bound of the lateral pressure of the supporting structure under the combined influence of the caves and structural planes were developed, which can be used to assess the safety factor of a rock mass and to calculate the lateral pressure under complex geological conditions.
\end{abstract}

Keywords: Karst cave development, rock foundation pit, upper bound analysis, rock lateral pressure

Corresponding author at: State Key Laboratory for Geomechanics and Deep underground Engineering, China University of Mining and Technology, Xuzhou, Jiangsu 221116, China.

E-mail address: 137112492@qq.com (Jin Xu).

\section{Introduction}

A variety of methods have been developed to study the stability of soil slopes in foundation pits. However, for rock slopes, the current consensus is that the failure of rock slopes is related to the structure of the rock mass or the structural plane [1], but the failure mechanism has not been fully identified.

Current theoretical methods for analyzing slope stability in foundation pits mainly include the limit equilibrium method [2-6], limit analysis method [711], numerical analysis [12-15], fuzzy analysis [16-18], and reliability analysis [19-21]. There are few studies of the stability of rock slopes in areas where karst caves are developed. This is primarily due to the difficulty of the transformation between a numerical model of karst caves and theoretical analysis.

The existing numerical models used to analyze the influence of karst caves on the stability of foundation pits are 
generally stochastic geological models established using the Monte Carlo method. Such methods are only applicable to specific areas and rely heavily on geological exploration data. The analysis results are only applicable to certain engineering conditions and thus have great limitations. In the theoretical analysis of karst caves, the safety factor is generally reduced based on engineering experience and the overall stability, but this method is unable to analyze the influences of such factors as the position and shape of karst caves on the final fracture surface. For caves in certain positions, the positional relationship to the structural plane may change the original failure path along the structural plane. Therefore, the method of reducing or increasing the safety factor does not conform to the actual situation.

\section{Failure Modes of Rock Slopes containing Differently Shaped Karst} Caves

In this study, a 2-D plane strain model was used to simulate the failure of a rock mass under different cave shapes and positions.

The foundation pit model is shown in Figure 2-1, The ideal elastoplastic constitutive equation, which follows the Mohr-Coulomb criterion and the nonassociated flow rule, was used for the model. The parameters of the rock mass and structural planes are presented in Table 2-1 and Table 2-2。

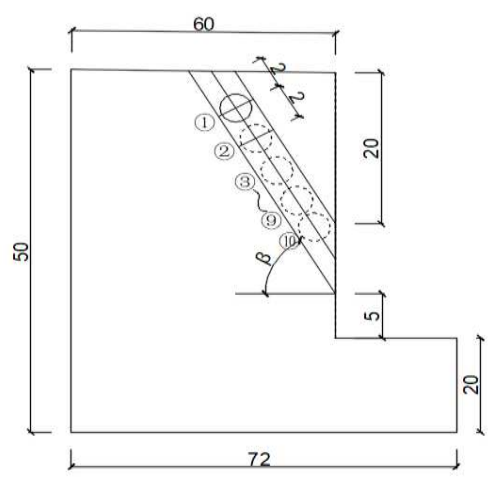

Figure 2-1 Numerical model of the foundation pit (unit: m)

Limestone was the analysis subject. According to the Engineering Geology Handbook (Fifth Edition), the middle values of the empirical ranges of the mechanical parameters of weathered limestone were taken as the model parameters. The parameters of the main slip surface were determined based on fully weathered type IV clay. The inclination angle $\beta$ of the slope's structural plane ranged from $60^{\circ}$ to $80^{\circ}$. From the upper structural plane to the bottom of the foundation pit, a cave calculation point was set up every $2 \mathrm{~m}$, and the failure modes at the 10 points were recorded under each set of working conditions. The apparent distance between the parallel structural planes and the excavation surface was $5 \mathrm{~m}$, and the true distance varied with the inclination of the structural plane in Figure 2-1。

In order to facilitate the description of the influence of the karst cave's shape 
on the failure mode of the foundation pit, the diameter-to- distance ratio (DDR) was introduced, which is defined as the ratio of the diameter of a circular cave (or the major axis of an elliptical cave) to the true distance between the structural planes. The DDR ranged from 0.9 to 0.2.

\subsection{Influence of the Inclination Angle} of the Structural Plane on the Failure Mode of the Rock Slope

Structural planes with varying inclination angles (i.e., $60^{\circ}, 70^{\circ}$, and $80^{\circ}$ ) were simulated, and Figure 2-2 presents the displacement map of the first calculation point under each inclination angle.

Taking a DDR of 0.9 as an example, the cave penetration failure occurred from point 1 at the top of the foundation pit under all three conditions. As the inclination angle of the structural plane increased, the angle between the crack and the lower structural plane also gradually increased, that is, the failure mode changed from shear failure to

tensile failure.

Figure 2-3 shows the end point of the penetration failure under different inclination angles. For an inclination angle of $60^{\circ}$, the penetration failure extended to point 3 ; and for an inclination angle of $70^{\circ}$, it extended to point 2 . In comparison, the penetration failure only reached point 1 when the inclination angle was $80^{\circ}$.

When the DDR was decreased 0.8 (Figure 2-4), the starting point of the penetration failure did not change, yet the end point of the penetration failure changed from point 3 (DDR=0.9) to the fourth point $(\mathrm{DDR}=0.8)$ for an inclination angle of $60^{\circ}$. However, for inclination angles of $70^{\circ}$ and $80^{\circ}$, the end point did not change. The failure of the rock bridge changed from shear failure to tensile failure. Thus, it can be concluded that the penetration failure mode of karst caves is related to the size of the rock bridge between the karst cave and the structural plane and the inclination of the structural plane.

Table 2-1Rock mass parameters of the calculation model

\begin{tabular}{clccccc}
\hline Name & $\begin{array}{c}\text { Density } \\
\left(\mathrm{kg} / \mathrm{m}^{3}\right)\end{array}$ & $\begin{array}{c}\text { Young's } \\
\text { modulus } \\
(\mathrm{Pa})\end{array}$ & $\begin{array}{c}\text { Poisson's } \\
\text { ratio }\end{array}$ & $\begin{array}{c}\text { Cohesion } \\
(\mathrm{Pa})\end{array}$ & $\begin{array}{c}\text { Internal } \\
\text { friction } \\
\text { angle }\left(^{\circ}\right)\end{array}$ & $\begin{array}{c}\text { Compressive } \\
\text { strength }(\mathrm{Pa})\end{array}$ \\
\hline Limestone & 2300 & $21.0 \mathrm{e} 9$ & 0.22 & $3.0 \mathrm{e} 6$ & 30 & $1.0 \mathrm{e} 6$ \\
\hline Name & Table 2-2Structural plane parameters of the calculation model & \\
\hline \multicolumn{2}{c}{$\begin{array}{c}\text { Normal } \\
\text { stiffness }(\mathrm{Pa})\end{array}$} & $\begin{array}{c}\text { Shear } \\
\text { stiffness } \\
(\mathrm{Pa})\end{array}$ & $\begin{array}{c}\text { Cohesion } \\
(\mathrm{Pa})\end{array}$ & $\begin{array}{c}\text { Internal } \\
\text { friction } \\
\text { angle }\left(^{\circ}\right)\end{array}$ & Compressive \\
\end{tabular}




\begin{tabular}{|c|c|c|c|c|c|}
\hline $\begin{array}{l}\text { Structural } \\
\text { plane IV }\end{array}$ & $2.0 \mathrm{e} 9$ & $1.0 \mathrm{e} 9$ & $2.0 \mathrm{e} 5$ & 15 & $1.0 \mathrm{e} 5$ \\
\hline
\end{tabular}

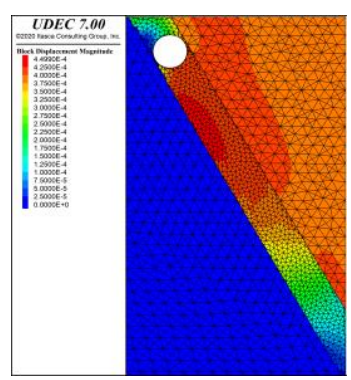

inclination angle of $60^{\circ}$,

$$
\text { point } 1
$$

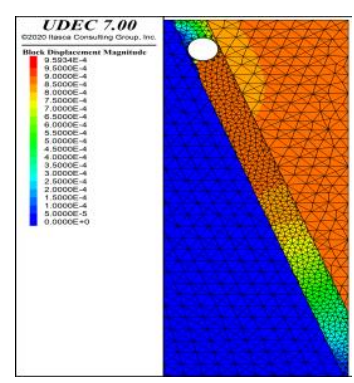

inclination angle of $70^{\circ}$,

$$
\text { point } 1
$$

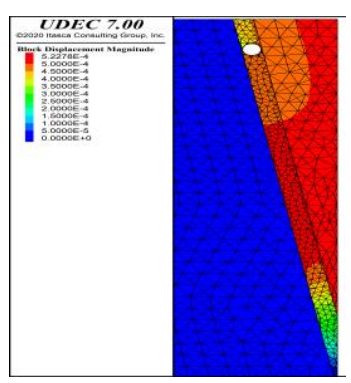

inclination angle of $80^{\circ}$, point 1

Figure 2-2 Displacement of the starting point of the penetration failure under different inclination angles of the structural plane $(\mathrm{DDR}=0.9)$

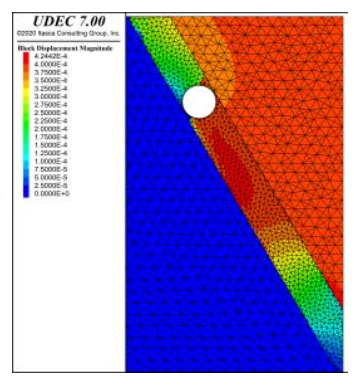

inclination angle of $60^{\circ}$,

$$
\text { point } 3
$$

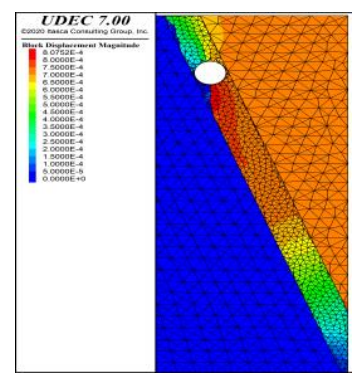

inclination angle of $70^{\circ}$, point 2

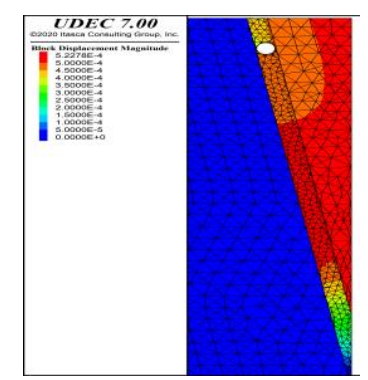

inclination angle of $80^{\circ}$, point 1

Figure 2-3 Displacement of the starting point of the penetration failure under different inclination angles of the structural plane $(\mathrm{DDR}=0.9)$

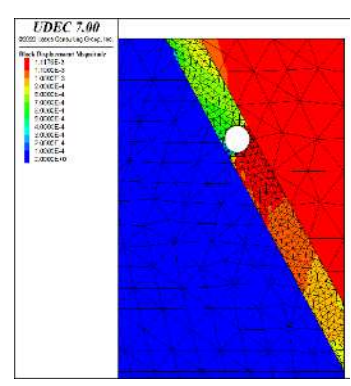

inclination angle of $60^{\circ}$, point 4

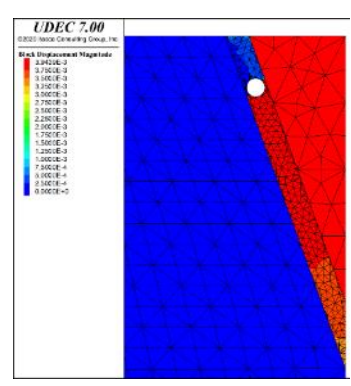

inclination angle of $70^{\circ}$, point 2

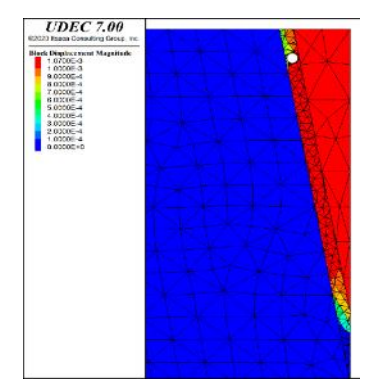

inclination angle of $80^{\circ}$, point 1

Figure 2-4 Displacement of the starting point of the penetration failure under different inclination angles of the structural plane $(\mathrm{DDR}=0.8)$ 


\subsection{Influence of the Shape of a Karst}

\section{Cave between Parallel Structural}

\section{Planes on the Failure Mode}

In order to analyze the influence of the shape of the cave on the failure mode of a rock mass between structural planes, elliptical caves with the same DDR were simulated. The angles of the major axis were set as $0^{\circ}, 40^{\circ}, 80^{\circ}$, and $120^{\circ}$. Taking the horizontal axis as the reference, the was major axis rotated clockwise. The results are shown in Figure 2-5。

When the major axis of the cave was horizontal $\left(0^{\circ}\right)$, the penetration failure extended along the two ends of the major axis to the parallel structural planes. The upper rock bridge underwent tensile failure, and the lower rock bridge underwent shear failure. When the angle was increased to $40^{\circ}$, the starting point of the penetration failure extended from the top of the foundation pit to the position of the karst cave, and the failure of the upper rock bridge changed from tensile failure to shear failure. Then, at $80^{\circ}$, the penetration failure extended towards the

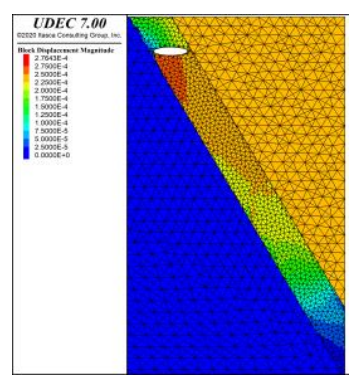

$0^{\circ}$

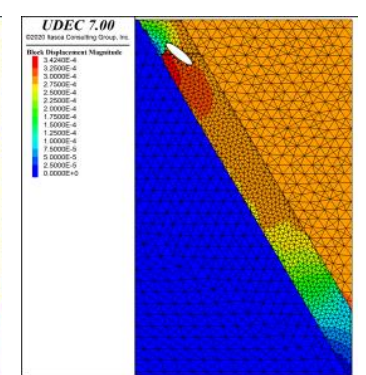

$40^{\circ}$

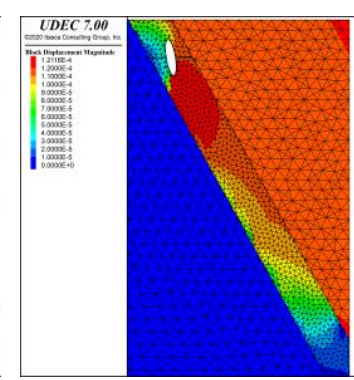

$80^{\circ}$

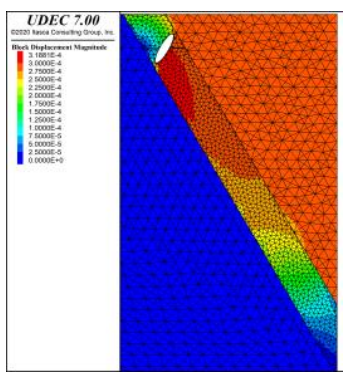

$120^{\circ}$

Figure 2-5 Failure modes of elliptical caves with different angles at point 1 for an inclination angle of $60^{\circ}(\mathrm{DDR}=0.9)$ 


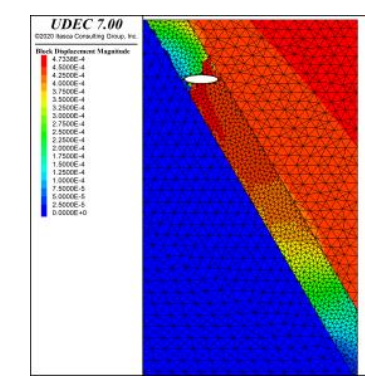

$0^{\circ}$

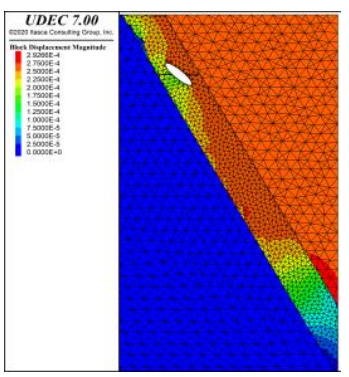

$40^{\circ}$

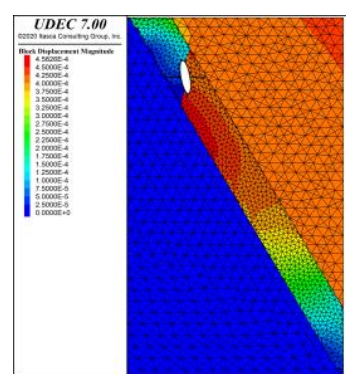

$80^{\circ}$

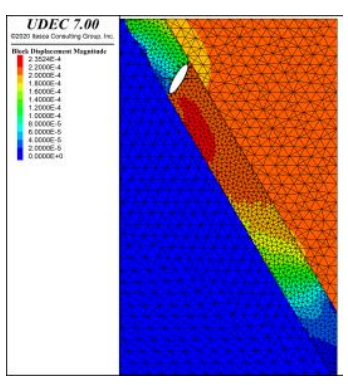

$120^{\circ}$

Figure 2-6 Failure modes of elliptical caves with different angles at point 2 for an inclination angle of $60^{\circ}(\mathrm{DDR}=0.9)$

Due to space limitations, the conditions at other inclination angles will not be discussed here. By changing the shape of the cave, the DDR, and the angle of the major axis, the failure at the 10 calculation points was analyzed and the conclusions that follow were obtained.

(1) For inclination angles of $60^{\circ}-$ $80^{\circ}$, the presence of karst caves may cause penetration failure of the structural plane. However, there was a minimum DDR value for the occurrence of penetration failure at each inclination angle. When the DDR was less than the minimum value, overall slip failure occurs.

(2) For a given DDR value, as the inclination of the structural surface increased, the penetration position of the cave with a circular shape gradually moved to the top of the foundation pit, that is, the area of overall rock mass failure increased.

(3) Regarding the influence of the major axis angle of the elliptical cave on the occurrence of penetration failure, when the inclination angle of the structural plane was $60^{\circ}$ and $70^{\circ}$, and the major axis angle was $0^{\circ}-40^{\circ}$ and $80^{\circ}-$ $120^{\circ}$, the cave underwent penetration failure. When the major axis angle was $40^{\circ}-80^{\circ}$, overall slip failure occurred.

\section{Penetration Paths of Karst Cave Groups Based on Single Cave Failure Mode}

Karst caves sometimes appear in groups in the slopes of foundation pits. In order to simplify the theoretical analysis of karst cave groups, we analyzed the feasibility of substituting karst cave groups with a single cave to obtain the same failure path.

Taking the structural plane with an inclination of $60^{\circ}$ as an example (Figure 3-1), an asymptotic line with a DDR of 0.9 was drawn parallel to the structural plane. Then, 4 failure paths were selected based on possible rock failure angles. Path 1 was perpendicular to the line and $30^{\circ}$ from the horizontal plane, path 2 was 
$45^{\circ}$ from the horizontal plane, path 3 was $60^{\circ}$ from the horizontal plane (the internal friction angle of the rock was $30^{\circ}$ ), and path 4 was perpendicular to the horizontal plane.

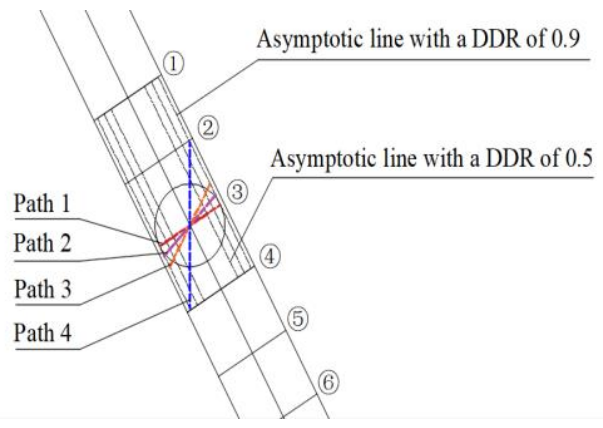

Figure 3-1 Similar failure modes of karst cave groups and circular karst cave

In this analysis, the DDR of a single cave was taken as the reference, the total DDR value of the cave group was changed, and the parameters of the cave group and the minimum total DDR needed to achieve similar failure paths were determined. For simplification, the distance between each karst cave was the same, and four working conditions were simulated (i.e., 3, 5, 7, and 9 karst caves). The cloud diagram and the substitution scheme are shown in Figure 3-2 and Table 3-1 respectively.

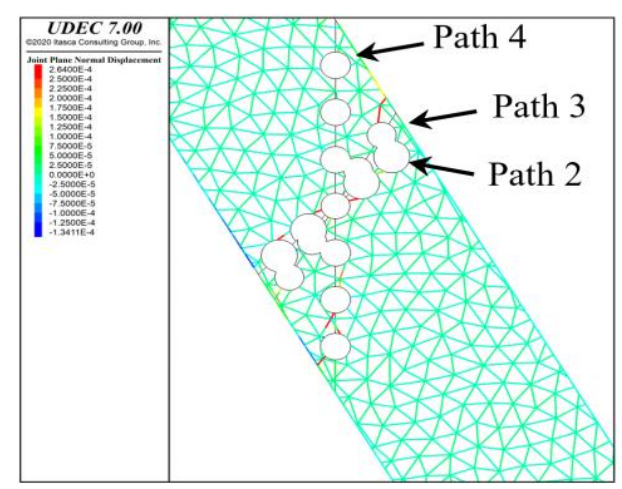

Figure 3-2 Penetration failure paths of karst cave groups

It can be seen from Table 3-1 that by conducting a simple analysis of the distribution of the karst cave group, the single cave substitution parameter with the same failure mode can be quickly determined, thereby acheiving simplified analysis of the karst cave group.

Table 3-1

Table 3-1 Karst cave group substitution table

\begin{tabular}{|c|c|c|c|c|c|c|c|c|c|c|}
\hline \multicolumn{5}{|c|}{ Parameters of single cave } & \multicolumn{6}{|c|}{ Parameters of cave groups } \\
\hline No. & $\begin{array}{l}\text { Failure } \\
\text { path }\end{array}$ & $\begin{array}{l}\text { radius/major } \\
\text { semi- } \\
\text { axis }(\mathrm{mm})\end{array}$ & DDR & $\begin{array}{l}\text { Range } \\
\text { of } \\
\text { major } \\
\text { and } \\
\text { minor } \\
\text { axis } \\
\text { ratio }\end{array}$ & $\begin{array}{l}\text { Radius } \\
(\mathrm{mm})\end{array}$ & $\begin{array}{l}\text { Cave } \\
\text { distance } \\
(\mathrm{mm})\end{array}$ & $\begin{array}{c}\text { Analysis } \\
\text { path }\end{array}$ & $\begin{array}{c}\text { Number } \\
\text { of } \\
\text { caves }\end{array}$ & $\begin{array}{l}\text { Total } \\
\text { DDR }\end{array}$ & Failure mode \\
\hline 1 & 1 & 1125 & 0.9 & $3 \sim 9$ & 250 & 875 & 1 & 3 & 0.6 & Overall \\
\hline 3 & 1 & 1000 & 0.8 & $3 \sim 5$ & 200 & 463 & 1 & 5 & 0.8 & Overall \\
\hline
\end{tabular}




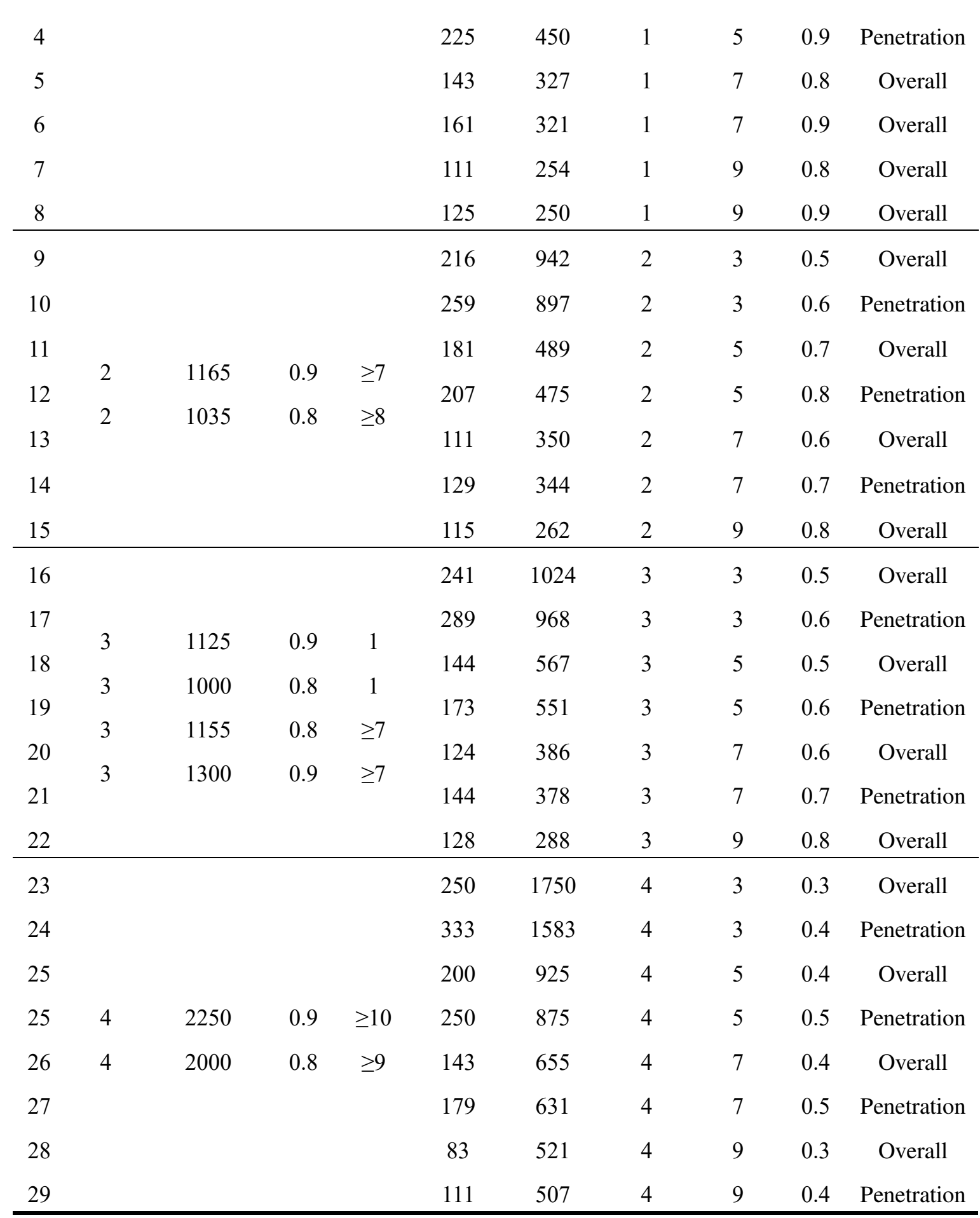

Note: (1) The total diameter-to-distance ratio (DDR) of the karst cave group is the ratio of the diameter of all of the substitutive karst caves on the specified path and the length of the failure path. (2) The penetration failure mode refers to penetration along the cave group, and the other failure modes are regarded as overall failure.

(3) Cave distance refers to the distance between the centroids of the karst caves. 


\section{Stability Analysis of a Rock} Slope Based on the Upper Bound

\section{Method}

In the previous section, based on the failure characteristics of a single cave with different shapes at different positions, the substitution schemes for cave groups to achieve similar failure paths were presented. In this section, theoretical analysis of the penetration failure of a single cave between parallel structural planes is carried out.

\subsection{Derivation of Slope Stability} Analysis Equation Based on the

\section{Upper Bound Method}

The results of the numerical simulation revealed that when the cave underwent penetration failure, the angle between the failure path and the horizontal plane was generally $45^{\circ}-90^{\circ}$. When the upper bound method is used for the analysis, a solution error for a $15^{\circ}$ change in the angle of failure is less than $1 \%$ [22]. Therefore, for high-inclination rock slopes with karst caves, statistics and kinematics of the plastic limit analysis approach can be used to determine the upper bound of the true solution of the slope stability.

It is assumed that the rock mass is a rigid body that will not be damaged under external forces and gravity. Moreover, it is assumed that the displacement of the adjacent structural planes is continuous.
Then, in the upper bound analysis, the internal energy represents the internal energy dissipation rate of the unstable rock mass and the velocity section. The power of external force includes the virtual power of the equivalent load produced by the rock mass's own weight on the velocity field. The internal energy dissipation rate of the system is equal to the external force power, and thus, the virtual power equation is as follows:

$$
\dot{W_{\text {lnt }}}=\dot{W}_{\text {ext }}
$$

As is shown in Figure 4-1 As is shown in Figure 4-1, DE is a straight line, and $E F$ is approximately a logarithmic spiral curve. $O E$ is the starting point of the logarithmic spiral, and point $D$ is the starting point of the rock bridge failure. $D K$ is a constructed virtual working surface, which is subjected to the gravity of the upper rock mass $A C D K$. The angle between $B D$ and $D C$ is $45^{\circ}+\varphi / 2 . H_{C}$ is the depth of the lower structural plane on the slope.

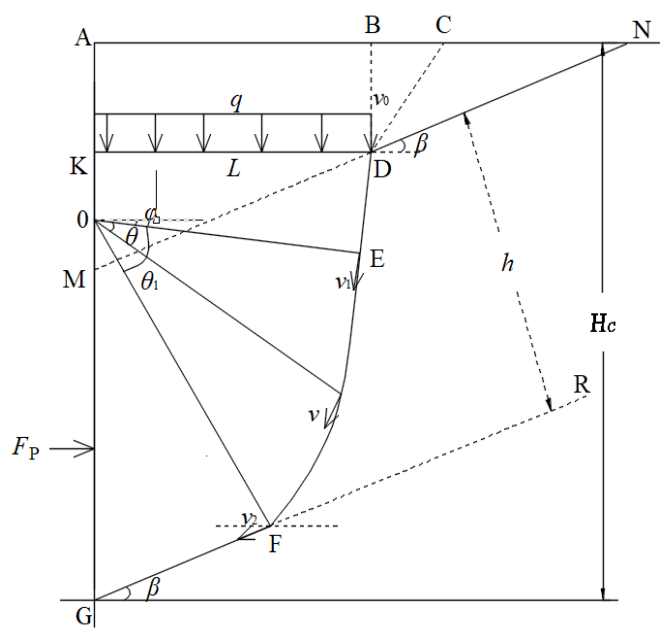


Figure 4-1 Upper bound analysis model for stability of rock slopes with structural plane and karst cave development

$c_{1}$ and $\varphi_{1}$ are the shear strength indices of the rock mass; and $c_{2}$ and $\varphi_{2}$ are the shear strength indices of the structural plane. If $K$ is the safety factor of the foundation pit, then, the reduced strength parameter is

$$
\begin{array}{cc}
\tan \varphi_{m 1}=\frac{\tan \varphi_{1}}{K} & c_{m 1}=\frac{c_{1}}{K} \\
\tan \varphi_{m 2}=\frac{\tan \varphi_{2}}{K} & c_{m 2}=\frac{c_{2}}{K}
\end{array}
$$

The relationship between $v_{0}, v_{1}, v_{2}$, and $v$ can be expressed as

$$
\begin{aligned}
& v_{0}=v_{1} \cdot \cos \varphi_{m 1} \\
& v=v_{1} \cdot e^{\theta \tan \varphi_{m 1}} \\
& W_{\text {total }}=W_{B C E O}+W_{O E F}+W_{q}+W_{O F G}+W_{P}
\end{aligned}
$$

$$
v_{2}=v_{1} \cdot e^{\theta_{1} \tan \varphi_{m 1}}
$$

The total work of the internal forces $E_{\text {total }}$ is:

$$
\begin{aligned}
& E_{\text {total }}=c_{m 1} \cdot v_{1} \cdot \cos \varphi_{m 1} \overline{D E}+ \\
& \frac{c_{m 1} \cdot v_{1} \cdot v_{0}^{2}}{r_{0} \tan \varphi_{m 1}}\left(e^{2 \theta_{1} \tan \varphi_{m 1}}-1\right)+E_{F G}
\end{aligned}
$$

where:

$$
\begin{aligned}
& \overline{D E}=L \cdot \tan \beta-\frac{r_{0} T}{\cos \left(90-\varphi_{m 1}-\theta_{1}\right)}+\frac{h}{\cos \beta}+ \\
& r_{0} \cdot \sin \varphi_{m 1} \\
& \text { and } T=e^{\theta_{1} \tan \varphi_{m 1}}
\end{aligned}
$$

The total work of the external forces is equal to the sum of the work done by the weight of the sliding rock mass, the earth pressure, the external force equivalent to the weight of the overlying rock, and the supporting force.

where $W_{B C E O}=\gamma \cdot v_{1} \cdot \cos \varphi_{m 1}\left(\overline{B O} \cdot L+\frac{1}{2} r_{0}^{2} \sin \varphi_{m 1} \cos \varphi_{m 1}\right)$

$W_{q}=q \cdot L \cdot v_{1} \cdot \cos \varphi_{m 1}$

$W_{P}=F_{p} \cdot v_{1} \cdot T$

and $W_{O E F}=\frac{1}{2} \gamma \cdot r_{0}^{2} \cdot v_{1} \cdot \frac{T^{3} \cdot\left[\left(3 \tan \varphi_{m 1} \cdot \cos \left(\varphi_{m 1}+\theta_{1}\right)\right)+\sin \left(\varphi_{m 1}+\theta_{1}\right)\right]-4 \sin \varphi_{m 1}}{1+9 \tan ^{2} \varphi_{m 1}}$

$$
E_{\text {total }}=W_{\text {total }}
$$

The above equation can then be rewritten as

$$
A L^{2}+B L+C r_{0}^{2}+D r_{0}+E r_{0} L+F=0
$$

where $A=\gamma \cos \varphi_{m 1} \cdot \tan \beta$

$$
\begin{aligned}
& B=\gamma \cos \varphi_{m 1} \frac{h}{\cos \beta}-c_{m 1} \cdot \cos \varphi_{m 1} \tan \beta+q \cos \varphi_{m 1} \\
& C=\frac{1}{2} \gamma\left\{\frac{T^{3} \cdot\left[\left(3 \tan \varphi_{m 1} \cdot \cos \left(\varphi_{m 1}+\theta_{1}\right)\right)+\sin \left(\varphi_{m 1}+\theta_{1}\right)\right]-4 \sin \varphi_{m 1}}{1+9 \tan ^{2} \varphi_{m 1}}+T^{2} \cdot \cos \varphi_{m 2}\right. \\
& \left.\left.\tan \left(90-\varphi_{m 1}-\theta_{1}\right)\right\}+\frac{1}{2} \gamma \cdot \cos ^{2} \varphi_{m 1} \cdot \sin \varphi_{m 1}\right) \\
& D=-\frac{c_{m 1}\left(T^{2}-1\right)}{\tan \varphi_{m 1}}-c_{m 2} \cdot T^{2} \cos \varphi_{m 2} \cdot \tan \left(90-\varphi_{m 1}-\theta_{1}\right) \\
& E=-\gamma \cos \varphi_{m 1} \cdot \frac{T}{\cos \left(90-\varphi_{m 1}-\theta_{1}\right)} \\
& F=-c_{m} \cdot \cos \varphi_{m 1} \cdot \frac{h}{\cos \beta}+F_{p} \cdot T-\cos \varphi_{m 1} \cdot \sin \varphi_{m 1}
\end{aligned}
$$




$$
\begin{aligned}
& q=\left[(N-L)^{2} \frac{\sin _{\beta}^{2}}{\cos \beta} \cdot \frac{1}{2} \gamma+(N-L)^{2} \tan \beta \cdot \cos \beta \cdot \frac{1}{2} \gamma \tan \varphi_{m 2}-\right. \\
& \left.c_{m 2}(N-L) \tan \beta \cdot \gamma\right] / L \\
& \text { and } N=\left[H_{c}-\frac{h}{\sin \left(90^{0}-\beta\right)}\right] \cdot \tan \left(90^{\circ}-\beta\right)
\end{aligned}
$$

To find the position of the karst cave failure between the structural planes, that is, to obtain the minimum weight required for the overlying rock mass, the minimum value of $L$ is required. If $d L / d r_{0}=0$ 。

$$
\begin{aligned}
& 2 C r_{0}+D+E L=0 \\
L= & -\frac{2 C r_{0}+D}{E}
\end{aligned}
$$

and $L=f\left(\gamma, c_{m 1}, \varphi_{m 1}, \beta, r_{0}\right.$,

$\left.c_{m 2}, \varphi_{m 2}, H_{c}\right)$

The safety factor when the cave undergoes penetration failure and the supporting force $F_{p}=0$ can be expressed as

$$
K=f\left(\gamma, c_{m 1}, \varphi_{m 1}, \beta, L\right. \text {, }
$$$$
\left.c_{m 2}, \varphi_{m 2}, H_{c}\right)
$$

When the rock mass slides along the fracture surface, i.e., $\mathrm{K}<1$, the lateral pressure is

$$
\begin{aligned}
& F_{p}=-\left(A L^{2}+B L+C r_{0}^{2}+D r_{0}+\right. \\
& E r_{0} L-c_{m 1} \cdot \cos \varphi_{m 1} \cdot \frac{h}{\cos \beta}- \\
& \left.\cos \varphi_{m 1} \cdot \sin \varphi_{m 1}\right) / T \\
& F_{p}=f\left(\gamma, c_{m 1}, \varphi_{m 1}, \beta, L,\right. \\
& \left.c_{m 2}, \varphi_{m 2}, H_{c}, k\right)
\end{aligned}
$$

In the presence of caves, the rock mass parameters $\left(c_{1}, \varphi_{1}\right)$ were reduced according to the ratio of the major axis (or diameter) of the cave to the length of the failure path. Because the $\varphi_{1}$ value has little effect on the slope stability coefficient, the focus of the reduction was the $c_{1}$ value of the rock mass.

The above equations were programmed into MATLAB to obtain the solutions.

\subsection{Comparison Between Calculation and Simulation Results of the Safety Factor}

The simulation parameters $\left(c_{1}=300\right.$ $\mathrm{kPa}, \varphi_{1}=30^{\circ}, \mathrm{c}_{2}=144 \mathrm{kPa}, \varphi_{2}=30^{\circ}, \gamma=23$ $\mathrm{kN} / \mathrm{m}^{3}$, and $H_{\mathrm{C}}=25 \mathrm{~m}$ ) were substituted into Equation 4.11, and the safety factors under inclination angles of $60^{\circ}$ and $70^{\circ}$ were calculated. Figure 4-2 shows the relationship between the safety factor and the position of the cave centroid. For example, at an inclination angle of $60^{\circ}$ for the structural plane, the load of the overlying rock mass at point 3 obtained from the numerical simulation was 43.55 $\mathrm{kN} / \mathrm{m}, \mathrm{L}=9.63 \mathrm{~m}$. The theoretical safety factor $K$ was 1.24 , and the safety factor obtained from the simulation was 1.3, 
which is slightly larger than the theoretical result. The calculation points are shown in Figure 2-1.

Similar findings were obtained when the inclination angle of the structural plane was $70^{\circ}$. However, the theoretical value was slightly larger than the simulation result at point 1 , and the difference in the maximum safety factor was 0.08. Therefore, the difference between the theoretical result and the simulation result was minimal.

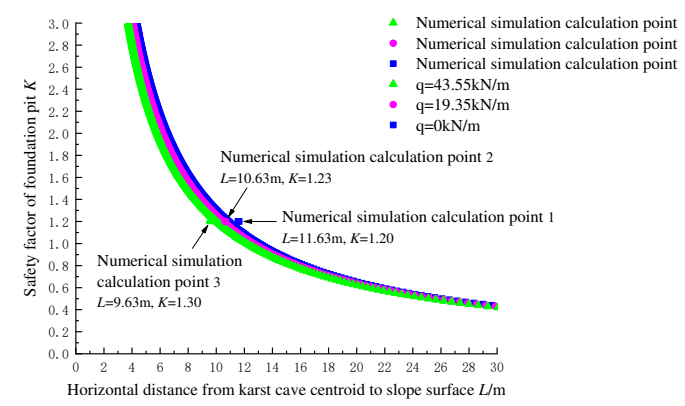

(a) $60^{\circ}$ inclination angle

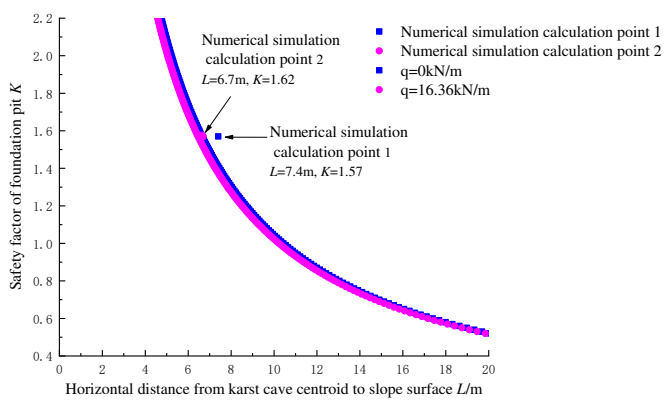

(b) $70^{\circ}$ inclination angle

Figure 4-2 Comparison of theoretical and numerical results

4.3 Influence of the Presence of a Structural Plane on the Stability of the Foundation Pit Based on the Upper Bound Method

Figure 4-3 shows the influence of the presence of a structural plane on the safety factor of the foundation pit, where $\mathrm{c} 1=300 \mathrm{kPa}, \quad \varphi 1=30^{\circ}, \quad \mathrm{c} 2=144 \mathrm{kPa}$, $\varphi 2=30^{\circ}, \gamma=23 \mathrm{kN} / \mathrm{m}^{3}$, and $\mathrm{HC}=25 \mathrm{~m}$. Figure 4-3(a), when the spacing of the structural planes was increased from $1 \mathrm{~m}$ to $8 \mathrm{~m}$, the safety factor of the caves at the same position increased and reached the highest value at $6 \mathrm{~m}$. The results for the curves between 6-8 m were the same, indicating a positive correlation between the safety factor of the foundation pit and the spacing of the structural planes. When the maximum safety factor is achieved, it remains unchanged even when the spacing continues to increase.

Figure 4-3(b) shows the relationship between the safety factor and the position of the cave under different inclination angles of the structural plane. It can be seen that when the inclination angle was $60^{\circ}$, the safety factor was the smallest; and when the inclination angle was $70^{\circ}$, the safety factor reached the maximum value. Moreover, the closer the cave was to the upper part of the foundation pit, the larger the depth of the lower structural plane was, and the smaller the influence of the inclination angle on the safety factor was. 


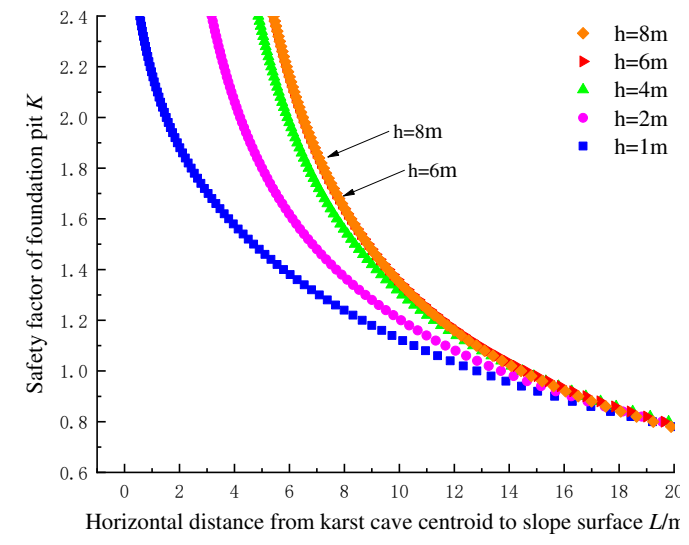

(a) structural plane spacing

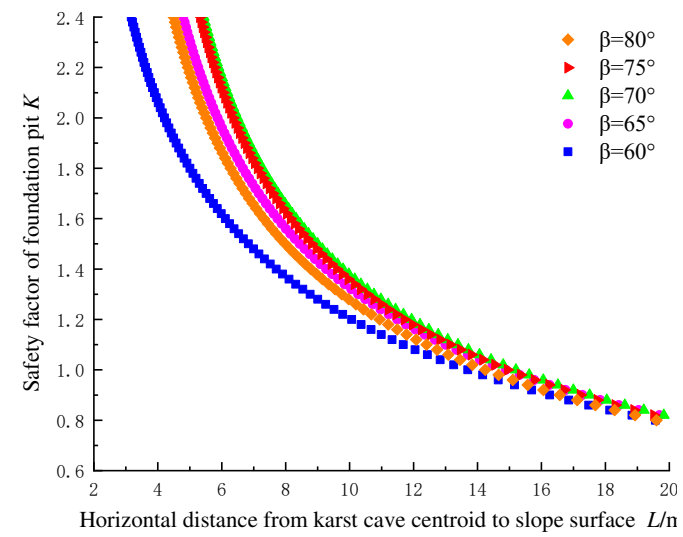

(b) inclination angle

Figure 4-3 Influence of the structural plane occurrence on the safety factor

\subsection{Influence of the Rock Mass} Parameters on the Stability of the Foundation Pit Based on the Upper

\section{Bound Method}

Figure 4-4 shows the influences of the mechanical parameters of the rock mass on the safety factor, where $c_{2}=144$ $\mathrm{kPa}, \varphi_{2}=30^{\circ}, \gamma=23 \mathrm{kN} / \mathrm{m}^{3}, \mathrm{~h}=2.25 \mathrm{~m}$, $\mathrm{H}_{\mathrm{C}}=25 \mathrm{~m}$, and $\beta=60^{\circ}$. As the cohesive force continuously decreased, i.e., the DDR increased, the influence of the cave at the same position on the safety factor of the foundation pit gradually increased, and the safety factor decreased. Moreover, the influence of the internal friction angle on the safety factor was relatively small. The five curves between $20^{\circ}$ to $40^{\circ}$ almost overlapped. Therefore, the internal friction angle did not significantly affect the safety factor of the foundation pit.

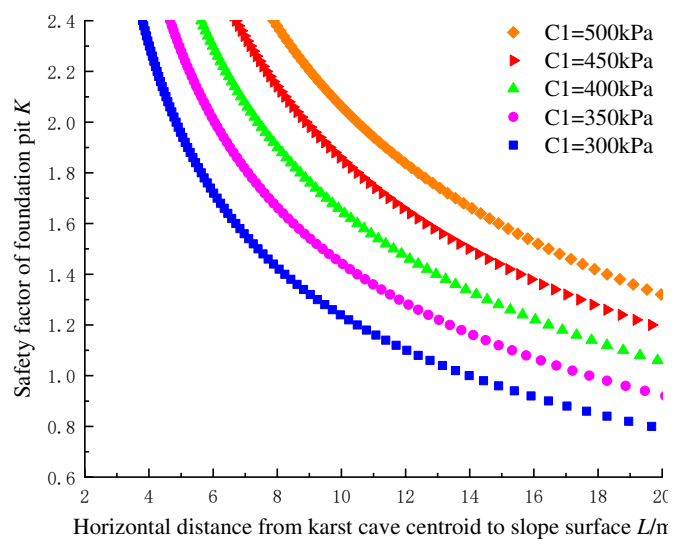

(a) rock mass cohesion

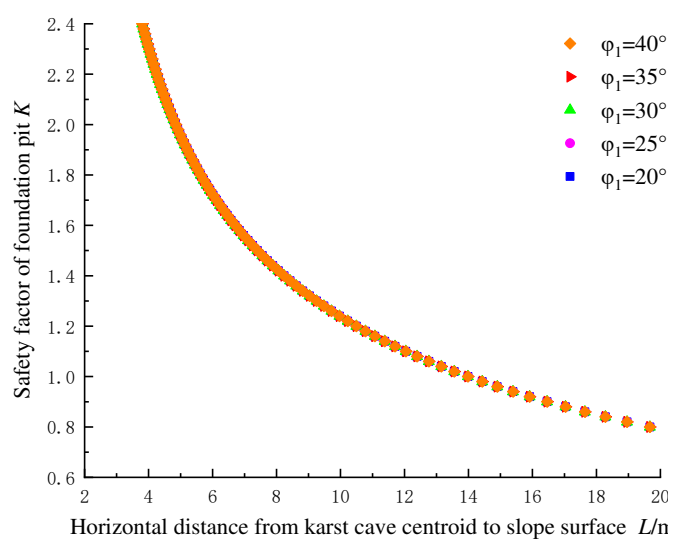

(b) internal friction angle

Figure 4-4 Influences of the rock mass parameters on the safety factor

\subsection{Influence of the Structural Plane} Parameters on the Stability the Foundation Pit Based on the Upper

\section{Bound Method}

Figure 4-5 shows the influences of the mechanical parameters of the structural plane on the safety factor of the foundation pit, where $\mathrm{c}_{1}=300 \mathrm{kPa}$, $\varphi_{1}=30^{\circ}, \gamma=23 \mathrm{kN} / \mathrm{m}^{3}, H_{\mathrm{C}}=25 \mathrm{~m}, \beta=60^{\circ}$, 
and $h=2.25 \mathrm{~m}$. By changing the cohesive force of the structural plane, it was found that the five curves intersect at a distance of $11 \mathrm{~m}$ from the centroid. Thus, when the distance was less than $11 \mathrm{~m}$, the lower the cohesion was, the lower the safety factor was. At distances of $>11 \mathrm{~m}$, the lower the cohesion was, the higher the safety factor was, but the magnitude of the increase was small. Similarly, by changing the internal friction angle of the structural plane, it was found that the influence on the safety factor was limited to a distance of $7 \mathrm{~m}$ from the cave centroid to the slope of the foundation pit. When the distance was $>7 \mathrm{~m}$, the safety factor was not affected. Therefore, the friction angle only affected the penetration of the karst cave at the bottom of the foundation pit.

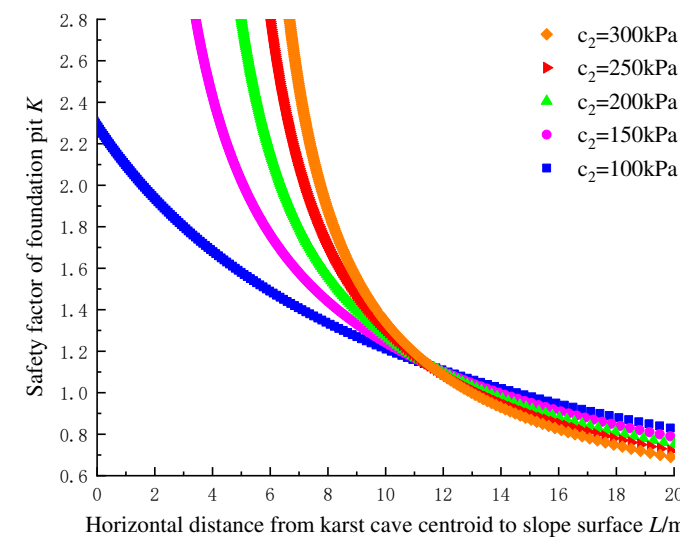

(a) rock mass cohesion

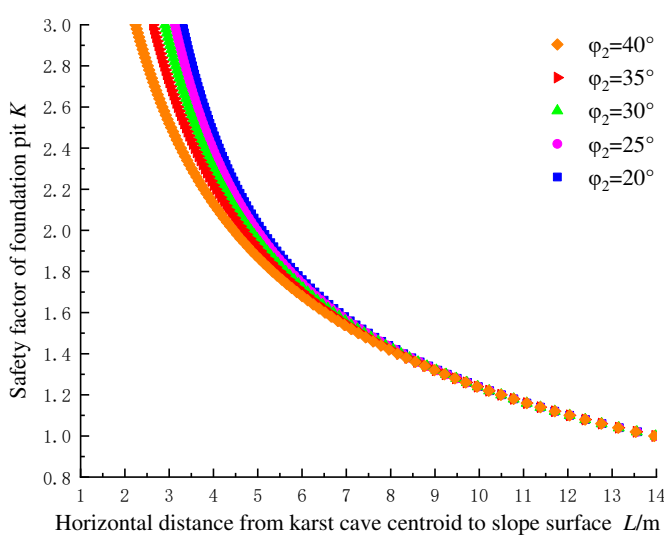

(b) internal friction angle

Figure 4-5 Influences of the structural plane parameters on the safety factor

For the same spacing of the structural planes, the relationship between the distance from the cave centroid to the slope of the foundation pit and the depth of the structural plane is shown in Figure 4-6, where $c_{1}=300 \mathrm{kPa}$, $\varphi_{1}=30^{\circ}, \mathrm{c}_{2}=144 \mathrm{kPa}, \varphi_{2}=30^{\circ}, \gamma=23 \mathrm{kN} / \mathrm{m}^{3}$, and $\mathrm{h}=2 \mathrm{~m}$. It can be seen that at the limit, when the structural plane's inclination angle was $60^{\circ}$, the minimum distance decreased as the depth of the structural plane increased. When the inclination angle was $80^{\circ}$, the minimum distance increased as the depth of the structural plane increased. For the other angles between $60^{\circ}$ and $80^{\circ}$, the minimum distance from the centroid to the slope surface initially increased and then decreased as the depth of the structural plane increased. Thus, the results show that the failure risk of the foundation pit was greater for an inclination angle of $60^{\circ}$ than for the other angles. 


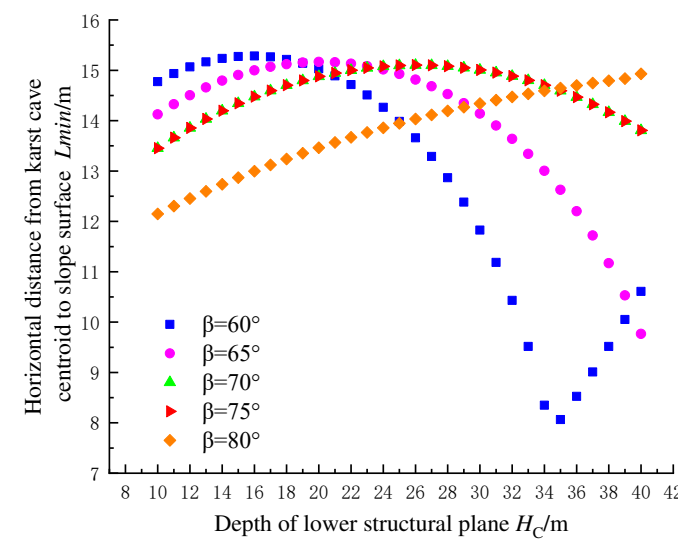

Figure 4-6 Relationship between the depth of the lower structural plane and the centroid position of the cave in the ultimate state

\subsection{Relationship Between the Rock} Mass Parameters and the Cave Position Based on the Upper Bound

\section{Method}

Figure 4-7 shows the influences of the rock mass parameters on the distance from the cave centroid to the slope surface. It can be seen that as the depth of the lower structural plane increased, the distance initially increased slowly, gradually decreased, and then increased again after reaching the minimum value. In Figure 4-7(a), when $\mathrm{c} 1=300 \mathrm{kPa}$, the minimum centroid distance occurred at a structural plane depth of about $34 \mathrm{~m}$. As the cohesion increased, the point of the minimum distance gradually increased. In foundation pit engineering, the excavation depth is generally less than 34 m. Therefore, for urban foundation pit engineering projects, as the depth of the lower structural plane increases, the distance for the cave to reach the ultimate state gradually decreases. The internal friction angle of the rock mass has little effect on the ultimate state of the foundation pit. The safety factor of the foundation pit is primarily determined by the position of the cave relative to the structural plane in Figure 4-7(b).

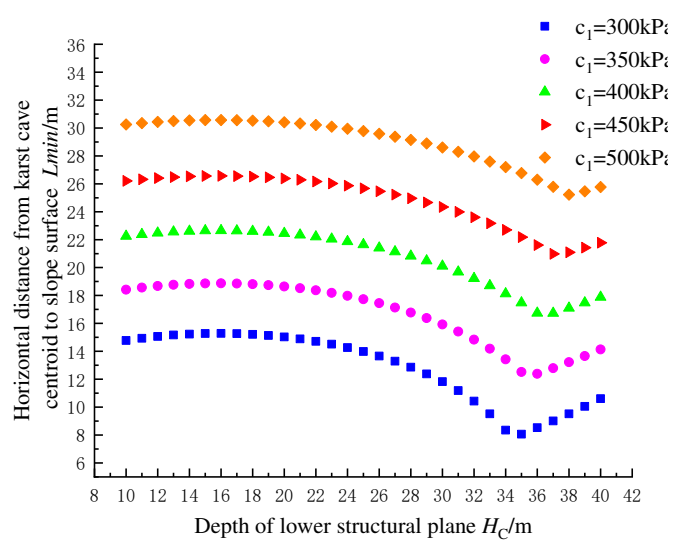

(a) rock mass cohesion

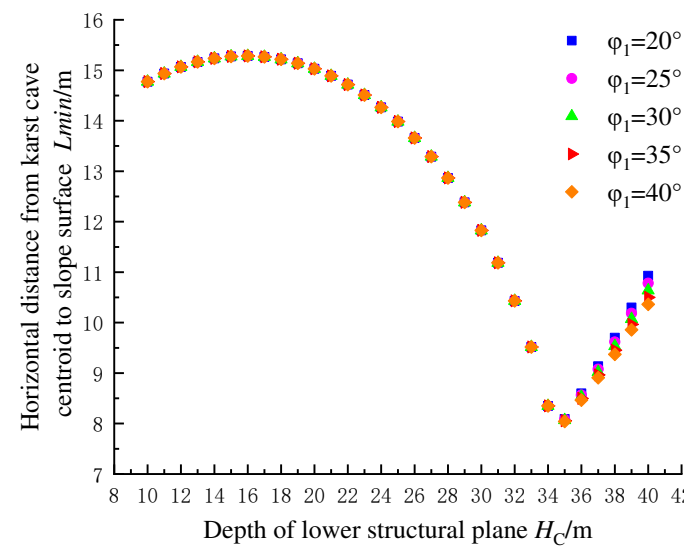

(b) internal friction angle

Figure 4-7 Influences of the rock mass parameters on the centroid position of the cave

Figure 4-8 shows the influences of the mechanical parameters of the structural plane on the position of the cave centroid in the ultimate state. The intersection point in Figure 4-8(a) occurred when the depth of the lower structural plane was about $28 \mathrm{~m}$. At this point, the position of the cave centroid at 
the ultimate state of the foundation pit did not change with the parameters of the structural plane. In Figure 4-8(a), there are two pivot points at $\mathrm{c} 2=100 \mathrm{kPa}$ and $\mathrm{c} 2=150 \mathrm{kPa}$, after which the change exhibits an increasing trend. When the internal friction angle of the structural plane changed Figure 4-8(b), there was a pivot point at each angle. As the internal friction angle increased, the position of the pivot point became deeper.

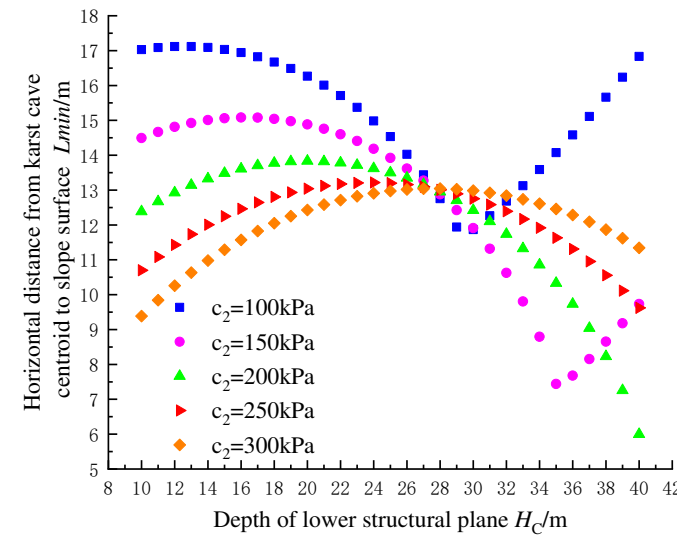

(a) rock mass cohesion

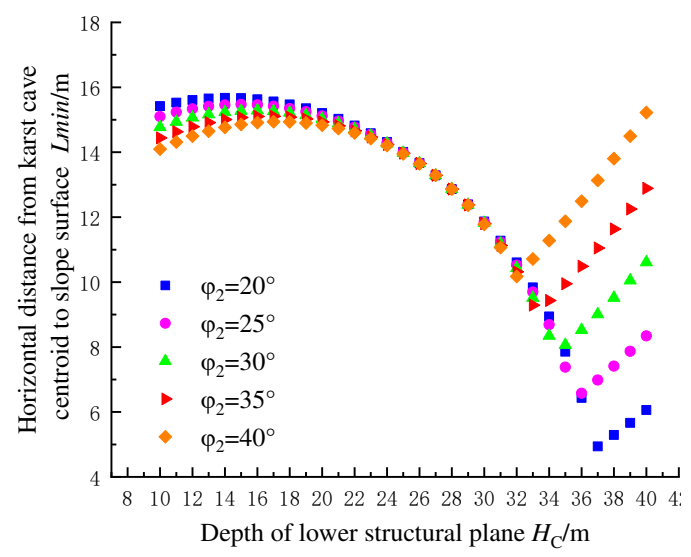

(b) internal friction angle

Figure 4-8 Influences of the structural plane parameters on the centroid position of the cave

\subsection{Supporting Force Calculation}

\section{Based on the Upper Bound Method}

In order to provide design guidance for engineering support systems, the safety assessment equation needs to reflect the supporting force required by the foundation pit when the safety factor is below the specified value. Figure 4-9 shows the relationship between the inclination angle of the structural plane and the supporting force (negative), where $\mathrm{c}_{1}=300 \mathrm{kPa}, \varphi_{1}=30^{\circ}, \mathrm{c}_{2}=144 \mathrm{kPa}$, $\varphi_{2}=30^{\circ}, \gamma=23 \mathrm{kN} / \mathrm{m}^{3}, \mathrm{~h}=2.25 \mathrm{~m}$, and $k=2.0$. When the inclination angle of the structural plane was changed from $60^{\circ}$ to $80^{\circ}$, the supporting force required by the foundation pit exhibited an increasingdecreasing-increasing pattern. The required supporting force was the largest when the inclination angle was $80^{\circ}$, and the distance from the cave centroid to the slope of the foundation pit was large. Therefore, the closer the cave between parallel structural planes is to the ground surface, the larger the required supporting force is. This finding is also supported by the variations in the strength coefficient of the supporting force in Figure 4-10

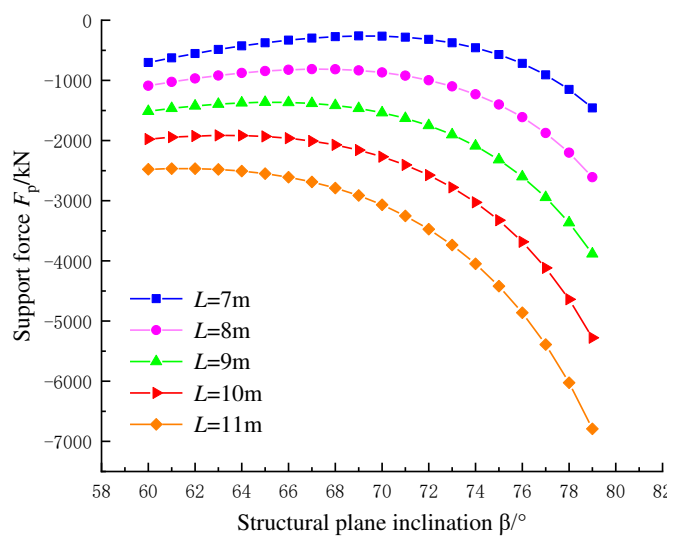
Note: the negative value of support force points out of the foundation pit 
Figure 4-9 Relationship between the supporting force and the inclination angle of the structural plane

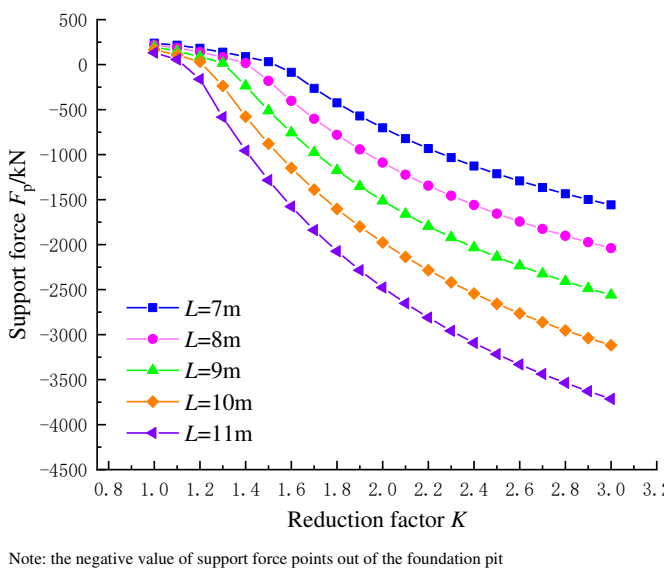

Figure 4-10 Relationship between the supporting force and the strength reduction coefficient

\section{Applicability of the Different} Lateral Pressure Calculation Methods for Rock Foundation Pits

Table 6-1 lists the common methods used to calculate the lateral soil pressure for a vertical slope with no overload at the top. Compared to other methods, the Rankine's lateral earth pressure formula (without considering the cohesion of the rock mass) obtained the smallest value. If the friction angle between the rock mass and the wall is considered, the results of the Coulomb's lateral earth pressure formula at $10 \mathrm{~m}$ and $20 \mathrm{~m}$ are much larger than those of the Rankine's lateral earth pressure formula at the same depths, but the results are similar at a depth of $30 \mathrm{~m}$. For rock foundation pits, if there is no outwardly inclined structural plane within $10 \mathrm{~m}$, the rock mass has a certain self-stabilizing ability. Therefore, Coulomb's lateral earth pressure formula may overestimate the pressure in the shallow region.

The wedge algorithm in Table 5-1 considers the friction angle between the interfaces, and the result is slightly larger than that of the Coulomb's active earth pressure when the friction angle between the soil and the rock is $18^{\circ}$. If the calculated depth of each layer is taken as the starting point of the slip surface (the fracture angle is $60^{\circ}$ ) and the earth pressure formula for slip along an outwardly inclined rigid structure surface is used, the earth pressure of each layer is increased higher than the result of the wedge algorithm. This is because the friction angle of the contact surfaces in the wedge algorithm is an empirical parameter, whereas the value used in this study was the minimum value of the empirical parameter. In the equation for calculating the slip along an outwardly inclined rigid structural surface, the shear strength value measured via indoor shear tests is used. The parameters of the two methods are different.

If the position of the karst cave is in the top of the pile, then Equation 4.13, which was obtained using the upper bound method, becomes the equation for non-karst cave conditions. When karst caves are not taken into account, the 
result of the upper bound method is slightly lower than that of the earth pressure of the slip along the outwardly inclined rigid structural surface. This is because the result of the upper bound method is the optimal solution that satisfies the energy equation, that is, the minimum residual thrust when the slope reaches the ultimate state. In a sense, the result calculated along the outwardly inclined structural plane satisfies the upper bound method. However, for the wedge algorithm, in order to obtain an accurate calculation result, an accurate value of the friction angle of the interface is needed.

\section{Conclusion}

In summary, the proposed slope stability equation based on the upper bound method can be used for slopes with and without karst caves. With the help of the karst cave group substitution scheme presented in Table 3-1, complex cave conditions can be simplified in the theoretical analysis of complex rock slopes.

Table 6-1 Earth pressure calculation table

\begin{tabular}{|c|c|c|c|c|c|c|c|c|}
\hline \multicolumn{9}{|c|}{ Basic calculation parameters } \\
\hline $\begin{array}{l}\text { Active earth } \\
\text { pressure } \\
\text { calculation } \\
\text { methods }\end{array}$ & $\begin{array}{c}\text { Soil } \\
\text { weight } \\
\left(\mathrm{kN} / \mathrm{m}^{3}\right)\end{array}$ & $\begin{array}{l}\text { Internal } \\
\text { friction } \\
\text { angle } \\
\left({ }^{\circ}\right)\end{array}$ & $\begin{array}{l}\text { Cohesion } \\
(\mathrm{kPa})\end{array}$ & $\begin{array}{l}\text { Poisson': } \\
\text { ratio }\end{array}$ & $\begin{array}{l}\text { Additional } \\
\text { load on } \\
\text { slope top } \\
\left(\mathrm{kN} / \mathrm{m}^{2}\right)\end{array}$ & $\begin{array}{c}\text { Angle } \\
\text { between } \\
\text { the } \\
\text { fracture } \\
\text { surface } \\
\text { and the } \\
\text { horizontal } \\
\text { plane }\left(^{\circ}\right)\end{array}$ & $\begin{array}{l}\text { Internal } \\
\text { friction } \\
\text { angle of } \\
\text { outwardly } \\
\text { inclined } \\
\text { structure } \\
\text { plane }\left(^{\circ}\right)\end{array}$ & $\begin{array}{c}\text { Cohesion } \\
\text { of } \\
\text { outwardly } \\
\text { inclined } \\
\text { structure } \\
\text { plane } \\
(\mathrm{kPa})\end{array}$ \\
\hline 23 & 45 & 150 & 0.17 & 0 & 60 & 15 & 0 & 0 \\
\hline $\begin{array}{l}\text { Active } \\
\text { calcula }\end{array}$ & $\begin{array}{l}\text { earth pre } \\
\text { tion met }\end{array}$ & $\begin{array}{l}\text { sure } \\
\text { ods }\end{array}$ & $\begin{array}{l}\text { Calculated } \\
\text { depth (m) }\end{array}$ & pres & $\begin{array}{l}\text { Active eart } \\
\text { ssure resul } \\
\text { force }(\mathrm{kN})\end{array}$ & & Comme & \\
\hline \multicolumn{3}{|c|}{$\begin{array}{c}\text { Rankine's active earth } \\
\text { pressure }\end{array}$} & $\begin{array}{c}0 \\
10 \\
20 \\
30\end{array}$ & & $\begin{array}{c}0 \\
197.3 \\
789.2 \\
1775.8\end{array}$ & \multicolumn{3}{|c|}{$\begin{array}{l}\text { Cohesion not considered; } \\
\text { failure angle: } 45^{\circ}+\varphi / 2\end{array}$} \\
\hline \multicolumn{3}{|c|}{$\begin{array}{c}\text { Coulomb's active earth } \\
\text { pressure }\end{array}$} & $\begin{array}{c}0 \\
10 \\
20 \\
30\end{array}$ & & $\begin{array}{c}0 \\
966.4 \\
1573.7 \\
1814.9\end{array}$ & \multicolumn{3}{|c|}{$\begin{array}{l}\text { Friction angle between } \\
\text { rock mass and wall: } \\
0.33 \varphi \text {; failure angle: } \\
45^{\circ}+\varphi / 2\end{array}$} \\
\hline \multicolumn{3}{|c|}{ Wedge algorithm } & $\begin{array}{c}0 \\
10 \\
20\end{array}$ & & $\begin{array}{c}0 \\
499.3 \\
1997.1\end{array}$ & \multicolumn{3}{|c|}{$\begin{array}{l}\text { Friction angle between } \\
\text { fill soil and rock } \\
\text { mass: } 18^{\circ} \text {; failure angle: }\end{array}$} \\
\hline
\end{tabular}




\begin{tabular}{cccc}
\hline & 30 & 4493.6 & $60^{\circ}$ \\
\hline Slip along the outwardly & 0 & 0 & \\
inclined rigid structure & 10 & 542.9 & Failure angle: $60^{\circ}$ \\
plane & 20 & 2171.7 & \\
& 30 & 4886.4 & No karst cave; failure \\
\hline Upper bound method & 0 & 0 & angle: $60^{\circ}$ \\
\hline
\end{tabular}

\section{Declaration of Competing Interest}

The authors declare that they have no known competing financial interest or personal relationships that could have appeared to influence the work reported in this paper.

\section{Acknowledgement}

This work was supported by the National Natural Science Foundation of China (grant no. 52074264, 51174194), the National Key Research and Development Program of China (grant no. 2016YFC0600903).

\section{References}

1. Wu SG. Stability and control of architectural rock slopes [D]. Chongqing University, 2005.

2. Sun JS. The numerial analysis of strip partition method[J]. Chinese Journal of Geotechnical Engineering, 1984, 12-16.

3. Ruan HY, Xu ZY. Limit equilibrium theory for slope engineering in complex rock masses[J]. Chinese Journal of Rock Mechanics and Engineering, 1993(1), 11-19.
4. Kumsar H, Aydan O, Ulusay R. Dynamic and static stability assessment of rock slopes against wedge failures[J]. Rock Mechanics and Rock Engineering. 2000, 33(1): 31-51.

5. $\mathrm{Xu} \mathrm{MY}$, Wang WM, Chen $\mathrm{SH}$. Research on the dangerous slidingblock combination of rock slopes[J]. Rock and Soil Mechanics, 2000(2), 148-151.

6. Chen XL. Quasi-static analysis of seismic stability of rock slope with double slide blocks[J]. Chinese Journal of Underground Space and Engineering, 2016, 12(5), 14031409.

7. Chen. Limit analysis and soil plasticity[M]. Elsevier Scientific Pub. Co., 1975.

8. Chen ZY, et al. Stability analysis of rock slopes $[\mathrm{M}]$. China Water Conservancy and Hydropower Press, 2005.

9. Zhang ZX, Xu Y, Huang X. Upper bound solution of limit analysis for stability of block- layered rock slope[J]. Journal of Tongji University (Natural Science), 2010, 38(5), 656-663.

10. Wang ZD, Xia YY, Xia GB, et al. Upper bound limit analysis method for stability analysis of bedding rock 
slopes[J]. Rock and Soil Mechanics, 2015, 36(2), 576-583.

11. Liu TP, Li SH, Liu XY. Study of dem and fem combination method for stochastic structural plane in jointed rock slope $[\mathrm{J}]$. Chinese Journal of Rock Mechanics and Engineering, 2014, 33(S1), 31143122.

12. Zhang SR, Tan YS, Wang C, et al. Research on deformation failure mechanism and stability of slope rock mass containing multi-weak interlayers[J]. Rock and Soil Mechanics, 2014, 35(6),1695-1702.

13. Lin H, Cao P, Li JT, et al. Numerical analysis of failure modes and stability of stratified rock slopes[J]. Rock and Soil Mechanics, 2010, 31(10), 3300-3304.

14. Kou XD, Zhou WY, Yang RQ, et al. Study on anchorage stability and mechanism of high slope in threegorge locks[J]. China Civil Engineering Journal, 2002(1), 68-73.

15. Gao YT, Xiao S, Wu SC, et al. Numerical simulation of the deformation and failure characteristics of consequent rock slopes and their stability[J]. Chinese Journal of Engineering, 2015, 37(11), 1403-1409.

16. Li YS, Chen WF, Li XP, et al. Stability assessment of rock slope based on fuzzy neural network[J].
Journal of Wuhan University of Technology, 2013, 35(1), 113-118.

17. Zhou N, Fu HL, Yuan Y. Evaluation approach of slope stability based on fuzzy neural network[J]. Chinese Journal of Underground Space and Engineering, 2009, 5(S2), 18261832.

18. Wang YX. Application of fuzzy mathematics to slope stability analysis[J]. Rock and Soil Mechanics, 2010, 31(9), 3000-3004.

19. Tao L, Guodong L, Cong W, et al. The probability and sensitivity analysis of slope stability under seepage based on reliability theory $[\mathrm{J}]$. Geotechnical and Geological Engineering. 2020 (prepublish).

20. Li K, Ju NP. Integrated application of Monte-Carlo simulation for landslide reliability analysis[J]. The Chinese Journal of Geological Hazard and Control, 2014, 25(1), 23 27.

21. Jiang SH, Ouyang S, Feng YW, et al. Reliability analysis of jointed rock slopes using updated probability distributions of structural plane parameters[J]. Rock and Soil Mechanics, 2021, 42(9), 2589-2599.

22. You ZJ, et al. Geotechnical plasticity theory and its application in underground engineering [M]. Coal Industry Press, 2017. 